\title{
Predictive factors of dengue severity in hospitalized children and adolescents in Rio de Janeiro, Brazil
}

\author{
Ralph Antonio Xavier Ferreira ${ }^{[1]}$, Claire Fernandes Kubelka ${ }^{[2]}$, \\ Luis Guillermo Coca Velarde ${ }^{[3]}$, Jorge Paulo Strogoff de Matos ${ }^{[4]}$, Laura Cunha Ferreira ${ }^{[1],}$ \\ Mariana Mancebo Reid ${ }^{[1]}$, Sérgio Setúbal ${ }^{[1]}$ and Solange Artimos de Oliveira ${ }^{[1]}$
}

\author{
[1]. Disciplina de Doenças Infecciosas e Parasitárias, Faculdade de Medicina, Universidade Federal Fluminense, Niterói, RJ, Brasil. \\ [2]. Laboratório de Imunologia Viral, Fundação Oswaldo Cruz, Rio de Janeiro, RJ, Brasil. \\ [3]. Disciplina de Estatística, Faculdade de Matemática e Estatística, Universidade Federal Fluminense, Niterói, RJ, Brasil. \\ [4]. Disciplina de Nefrologia, Faculdade de Medicina, Universidade Federal Fluminense, Niterói, RJ, Brasil.
}

\begin{abstract}
Introduction: Dengue is one of the most important mosquito-borne infections. Severe cases are more frequently observed in adults. However, in 2008, the State of Rio de Janeiro, Brazil, experienced a severe dengue epidemic that primarily affected children and caused many cases of dengue hemorrhagic fever (DHF) and death. Methods: A cross-sectional analytical study was conducted to examine laboratory diagnosis and clinical epidemiologic factors for confirmed dengue cases in patients aged less than 16 years, from January to June 2008, at a municipal hospital in the City of Rio de Janeiro, Brazil. Variables associated with severe outcomes and $P$ values less than .05 were evaluated by means of a logistic regression model. Results: Of the 419 dengue cases studied, 296 were classified as DHF and 123 as classical dengue. Six patients who had DHF died. In multivariate analysis, some laboratory and clinical variables were independently associated with DHF: age 5 years or older (odds ratio [OR], 4.94; 95\% confidence interval [CI], 1.30-18.71), abdominal pain (OR, 8.59; 95\% CI, 3.17-23.27), hepatomegaly (OR, 15.87; 95\% CI, 5.38-46.85), and positive tourniquet test (OR, 10.84; 95\% CI, 3.96-29.71). Hypoalbuminemia occurred more frequently than hemoconcentration in DHF cases, and high aminotransferase levels were associated with severity. Conclusions: Age greater than 5 years, abdominal pain, painful hepatomegaly, and positive tourniquet test were predictors of DHF. The high frequency of hepatic impairment suggests that acetaminophen should be avoided in severe cases of dengue.
\end{abstract}

Keywords: Severe dengue. Dengue hemorrhagic fever. Predictive factors. Children.

\section{INTRODUCTION}

Dengue, an arthropod-borne viral infection transmitted by mosquitoes, is a major public health problem in tropical and subtropical regions of the world. Dengue may be extremely severe $^{1,}$ with its case-fatality rate varying from $0.5 \%$ to $15 \%$, depending on the country ${ }^{2,3}$.

Unlike Asian countries, where dengue primarily affects children, most Brazilian dengue epidemics have affected adults ${ }^{3}$. Nevertheless, isolated outbreaks affecting children occurred in 2002 and 2006 to 2007 in the City of Manaus, in the Amazon State $^{4,5}$. In 2008, a sudden shift occurred in the epidemiologic profile of dengue cases in the State of Rio de Janeiro. At that time, there was a major increase in the proportion of cases in children aged less than 15 years, with a concurrent increase in the number of cases of dengue hemorrhagic fever (DHF)

Corresponding author: Dr. Ralph Antonio Xavier Ferreira.

e-mail: ralphantonioxavier@gmail.com

Received 13 February 2018

Accepted 31 August 2018 and deaths. This was the first large dengue epidemic affecting children in Brazil, at a time when knowledge about the natural course of the disease in children was scarce ${ }^{6}$.

The Hospital Municipal Jesus (HMJ), in the City of Rio de Janeiro, a pediatric public hospital, provides care for children from the entire State of Rio de Janeiro. During the 2008 epidemic, 445 pediatric patients were diagnosed with dengue, with most having the hemorrhagic form. In contrast, in the subsequent years of 2009 to 2016, 231 children were hospitalized with dengue, of which only 25 had confirmed $\mathrm{DHF}^{7}$. Because of the small number of studies on DHF in Brazilian children, this study was designed to better characterize the clinical and laboratory profile of the children hospitalized with dengue in a municipal hospital in Rio de Janeiro in 2008. The study aim was to identify factors associated with severe clinical forms of dengue.

\section{METHODS}

\section{Study population}

This cross-sectional analytical study used laboratory diagnosis and clinical epidemiologic data for children with 
confirmed dengue who were hospitalized from January to June 2008 at HMJ. All cases of DHF or classical dengue (CD) that fit the Brazilian Ministry of Health diagnostic criteria ${ }^{8}$ and were reported to the Brazilian Information System for Notifiable Diseases (SINAN) by the HMJ Epidemiology Service were included in the study. DHF was diagnosed based on the presence of fever, hemorrhagic signs, platelet count less than 100,000/ $\mu$, and plasma extravasation (as indicated by hematocrit increase of more than $20 \%$ from baseline levels, ascites, pleural effusion, or hypoalbuminemia) ${ }^{8}$. For the final classification of each case (CD or DHF), the most severe form described in the medical record was used.

Dengue cases were defined as (a) dengue fever confirmed by clinical and laboratory criteria; or (b) dengue fever confirmed by clinical and epidemiologic criteria. Clinical criteria are as previously defined ${ }^{8}$. Laboratory criteria included those previously defined plus the detection of specific IgM antibodies. The epidemiologic criterion was epidemiologic linkage to another confirmed case.

All data were extracted from hospital medical records and HMJ Epidemiology Service investigation forms. Cases were excluded if patient medical records could not be found, or if epidemiologic investigation forms contained insufficient information.

\section{Variables}

The variables included in the analysis were patients' age, sex, illness duration, clinical manifestations, dengue classification (CD or DHF), laboratory test results, month of hospitalization, and place of residence. Laboratory tests performed during the first two days of illness were grouped, as were those performed from the 11th to 15th days of illness, as the number of tests performed during these time intervals was small.

All tests were performed in the HMJ laboratory using an instrument for random access chemistry analysis (Targa 3000, Biotecnica Instrumentos, Rio de Janeiro, Brazil). Reference values were the same for all patient laboratory specimens: sodium, 135-145 mEq/1; aspartate aminotransferase (AST), up to $32 \mathrm{IU} / \mathrm{ml}$; alanine aminotransferase (ALT), up to $31 \mathrm{IU} / \mathrm{ml}$; albumin, $3.5-4.8 \mathrm{mg} / \mathrm{dl}$; white blood cell count, 5000 to 8000 leukocytes $/ \mathrm{ml}$; platelet count, greater than or equal to $150,000 / \mathrm{ml}$; and hematocrit, $51 \%$ for children aged 1 month or younger; $35 \%$ for children aged 2 to 6 months; $36 \%$ for children aged 7 months to 2 years; $37 \%$ for children aged 3 to 6 years; and $38 \%$ for children aged 7 years or older.

Serologic diagnosis of dengue was made using qualitative enzyme immunoassay of specific immunoglobulin M (IgM). Diagnoses were made at the Noel Nutels Central Public Health Laboratory, Rio de Janeiro, following the routine established by the municipality, in which serum should be collected on or after the seventh day of illness.

\section{Statistical analysis}

Data were expressed as frequencies, medians, means, and standard deviations. To determine the factors associated with DHF, chi-square tests were used for categorical variables and
Student's t-tests were used for continuous variables. Simple and multiple logistic regression models were used. Some clinical manifestations of DHF (i.e. hemorrhagic signs and plasma extravasation), were not included in the model because the study objective was to determine which factors predicted DHF. All statistical analysis were performed using S-Plus 8.0 software (TIBCO Software, Inc., Palo Alto, CA, USA). The graphs used to show laboratory test results were generated using GraphPad Prism version 5.0 for Windows (GraphPad Software, Inc., San Diego, CA, USA) using medians or means $\pm 1 \mathrm{SD}$.

\section{Ethical review}

This study was approved by the Research Ethics Committee of the Rio de Janeiro Municipal Health Department (number 236/08).

\section{RESULTS}

\section{Clinical-epidemiologic study}

During the study period, 445 pediatric patients with dengue were admitted to the HMJ. Of those, we excluded 26 cases with no medical records. Thus, of 419 cases included in this study, $329(78.5 \%)$ and $90(21.5 \%)$ cases of dengue were confirmed by clinical-laboratory and clinical-epidemiologic criteria, respectively. With respect to disease severity, 296 (70.6\%) cases were classified as DHF and 123 (29.4\%) cases as CD. Six of 296 (1.4\%) patients with DHF died; four of those deaths occurred within the first week of hospitalization.

The highest number of hospitalizations (38.0\%) occurred during the month of April, and most patients $(74.9 \%)$ were from the City of Rio de Janeiro. There were slightly more male patients $(53.0 \%)$ than female $(47.0 \%)$, and patients' age ranged from 1 month to 16 years (mean, 8.3 years). Of the 419 cases, $364(86.9 \%)$ occurred in patients aged 5 to 16 -years-old, with 270 out of 364 having DHF (Table 1). All patients had fever as the initial manifestation. The mean fever duration was 4.3 days, and $98.8 \%$ of the children were afebrile within 7 days of illness onset.

On univariate analysis, factors associated with DHF were age (5 years or older), abdominal pain, hepatomegaly, vomiting, fatigue, petechiae, positive tourniquet test, spontaneous gingival bleeding, and drowsiness (Table 1). After adjusting for these in the regression model, age (5 years or older), abdominal pain, hepatomegaly, and positive tourniquet test remained independently associated with DHF (Table 2).

Plasma leakage was diagnosed based on hypoalbuminemia (80.8\%), pleural effusion (78.7\%), rising hematocrit (70.0\%), ascites $(65.5 \%)$, and subcutaneous edema $(25.3 \%)$ in children with DHF.

\section{Laboratory results}

Platelets. Median platelet values for those with DHF and CD differed between days 3 to 8 and $(\mathrm{P}<0.01)$ and day $9(\mathrm{P}<0.05)$ (Figure 1A). The lowest platelet count observed was $2,900 / \mathrm{ml}$ for a patient with DHF and 10,000/ml for a patient with CD.

White blood cell counts. On days 3 and 4, the median leukocyte count was lower in patients with DHF compared 
TABLE 1: Univariate analysis of the clinical characteristics of patients with hemorrhagic dengue fever and classic dengue from January to June 2008.

\begin{tabular}{|c|c|c|c|c|c|}
\hline Characteristics & $\begin{array}{c}\text { DHF } \\
\mathbf{N}\end{array}$ & $\begin{array}{c}\mathrm{CD} \\
\mathrm{N}\end{array}$ & $P$ value & OR & $95 \% \mathrm{Cl}$ \\
\hline Age & & & $<0.0001$ & & \\
\hline$<5$ years old & 27 & 28 & & 1 & \\
\hline Fever & & & 0.4405 & & \\
\hline$>38.5^{\circ} \mathrm{C}$ & 166 & 64 & & & \\
\hline Length of fever & & & 0.1945 & & \\
\hline$<5$ days & 134 & 62 & & & \\
\hline$\geq 5$ days & 102 & 33 & & & \\
\hline Hepatomegaly & & & $<0.0001$ & & \\
\hline Yes & 207 & 9 & & 29.4 & $3.74-65.23$ \\
\hline No & 89 & 114 & & 1 & \\
\hline Abdominal pain & & & $<0.0001$ & & \\
\hline Yes & 215 & 12 & & 27 & $13.54-54.90$ \\
\hline No & 73 & 110 & & 1 & \\
\hline Fatigue & & & 0.0006 & & \\
\hline Yes & 200 & 59 & & 2.31 & $1.40-3.80$ \\
\hline No & 69 & 47 & & 1 & \\
\hline Petechiae & & & 0.0169 & & \\
\hline Yes & 142 & 43 & & 1.74 & $1.1-2.76$ \\
\hline No & 150 & 79 & & 1 & \\
\hline Gum bleeding & & & 0.0478 & 2.33 & $1.06-5.12$ \\
\hline Yes & 41 & 8 & & 1 & \\
\hline Yes & 38 & 2 & & 8.48 & $1.95-51.87$ \\
\hline No & 224 & 100 & & 1 & \\
\hline Muscle aches & & & 0.7785 & & \\
\hline Yes & 194 & 77 & & & \\
\hline No & 68 & 30 & & & \\
\hline Headache & & & 0.2410 & & \\
\hline Yes & 248 & 93 & & & \\
\hline No & 25 & 15 & & & \\
\hline Tourniquet test & & & $<0.0001$ & & \\
\hline Positive & 168 & 20 & & 15.32 & $7.22-32.48$ \\
\hline Negative & 17 & 31 & & 1 & \\
\hline Nose bleeding & & & 0.1660 & & \\
\hline Yes & 60 & 17 & & & \\
\hline No & 231 & 103 & & & \\
\hline Retroorbital pain & & & 0.2484 & & \\
\hline Yes & 37 & 21 & & & \\
\hline No & 207 & 79 & & & \\
\hline
\end{tabular}

OR: odds ratio; 95\% CI: 95\% confidence interval. DHF: dengue hemorrhagic fever. 
TABLE 2: Results of logistic regression model of the clinical characteristics of patients with dengue hemorrhagic fever and classical dengue hospitalized from January to June 2008.

\begin{tabular}{|c|c|c|c|c|c|c|}
\hline \multirow{2}{*}{ Characteristics } & \multicolumn{3}{|c|}{ Univariate } & \multicolumn{3}{|c|}{ Adjusted } \\
\hline & OR & $95 \% \mathrm{Cl}$ & $p$ value & OR & $95 \% \mathrm{Cl}$ & $p$ value \\
\hline Age (years) & 1.08 & $1.02-1.05$ & 0.0145 & & & \\
\hline yes & 3.20 & $1.80-5.72$ & & 4.94 & $1.30-8.71$ & \\
\hline no & 1.00 & & & & & \\
\hline no & 1.00 & & & 1.00 & & \\
\hline Hepatomegaly & & & $<0.0001$ & & & $<0.0001$ \\
\hline yes & 29.45 & $14.42-60.13$ & & 15.87 & $5.38-46.85$ & \\
\hline no & 1.00 & & & 1.00 & & \\
\hline Petechiae & & & 0.0129 & & & \\
\hline yes & 1.74 & $1.12-2.69$ & & & & \\
\hline no & 1.00 & & & & & \\
\hline Tourniquet test & & & $<0.0001$ & & & \\
\hline positive & 15.32 & $7.22-32.48$ & & 10.84 & $3.96-29.71$ & $<0.0001$ \\
\hline negative & 1.00 & & & 1.00 & & \\
\hline Somnolence & & & 0.0034 & & & \\
\hline yes & 8.48 & $2.03-35.49$ & & & & \\
\hline no & 1.00 & & & & & \\
\hline
\end{tabular}

OR: odds ratio; $\mathbf{9 5} \% \mathbf{C l}$ : $95 \%$ confidence interval.

to those with $\mathrm{CD}(\mathrm{P}<0.01)$. From day 5 to day 8 , however, leukocyte counts were higher in patients with $\mathrm{DHF}(\mathrm{P}<0.01$; Figure 1B). The lowest white cell count (less than 1000/ml) occurred in a single patient with DHF who died. Of the six patients with DHF who died, five had leukocytosis, neutrophilia, lymphopenia, and monocytosis after the fifth day of disease.

Hematocrit. Hemoconcentration was observed from day 3 to day 6 in patients with DHF. During this period, higher hematocrit levels were measured in patients with DHF compared to those with $\mathrm{CD}$ on days 3,4 , and $6(\mathrm{P}<0.01)$ as well as day $5(\mathrm{P}<0.05$; Figure 1C). Hemoconcentration in four patients with $\mathrm{CD}$ was attributed to dehydration.

Hemoglobin. Hemoglobin values differed for those with DHF and CD on days $4(\mathrm{P}<0.01), 5(\mathrm{P}<0.05)$, and $6(\mathrm{P}<0.01$; Figure 1D).

Aminotransferases. ALT and AST values were obtained for 404 and 406 patients, respectively. Levels of both enzymes increased during the first week of disease (especially in patients with DHF) and returned to normal by week 3. ALT (Figure 2A) and AST (Figure 2B) levels were higher for those with DHF compared to those with $\mathrm{CD}$ on each day of illness. Of the six patients with DHF who died, five had enzyme levels 30 times the normal values.

The association between painful hepatomegaly and AST elevation was evaluated for 406 cases. Of the 215 patients with painful hepatomegaly, 214 (99.5\%) had elevated AST levels. Of the 191 patients without hepatomegaly, $170(89.0 \%)$ had AST elevation. Children with hepatomegaly had a higher odd of having AST elevation compared to those without hepatomegaly (odds ratio $[\mathrm{OR}]=26.4 ; 95 \%$ confidence interval $[\mathrm{CI}]=3.52-198.52)$.

The association between painful hepatomegaly and ALT elevation was determined for 404 patients. Of the 213 patients with painful hepatomegaly, 174 (81.7\%) had elevated ALT levels. Of the $191(47.3 \%)$ patients without hepatomegaly, $125(65.4 \%)$ eventually developed ALT elevation. Those with painful hepatomegaly had 2.35-times the odds of having ALT elevation compared to those without painful hepatomegaly $(\mathrm{OR}=2.35 ; 95 \% \mathrm{CI}=1.49-3.72)$. Myalgia was not associated with ALT or AST elevation (data not shown).

Sodium. Serum sodium level was measured in 391 of the 419 patients, of whom 284 (72.6\%) had DHF and 107 (27.4\%) had 


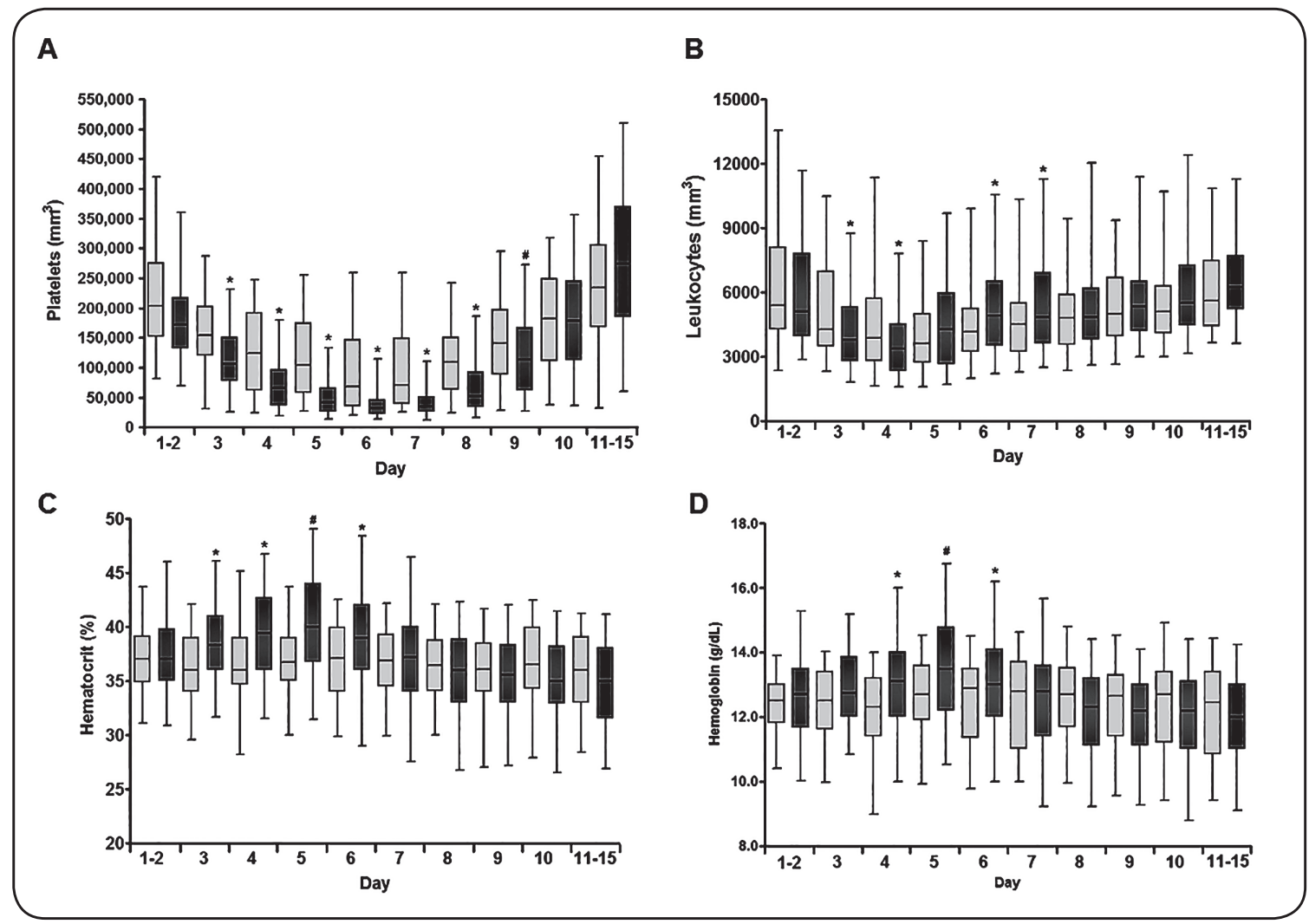

FIGURE 1: Box-plots for the A. Platelet, B. leukocyte, C. hematocrit, and D. hemoglobin levels in patients with dengue hemorrhagic fever (DHF) and classical dengue (CD) who were admitted to the Hospital Municipal Hospital Jesus from January to June 2008, according to elapsed days of illness. ${ }^{*} P<0.01$ vs. $C D$; ${ }^{*} P<0.05$ vs. CD. $\mathbf{n}$ DHF, $n$ DC.

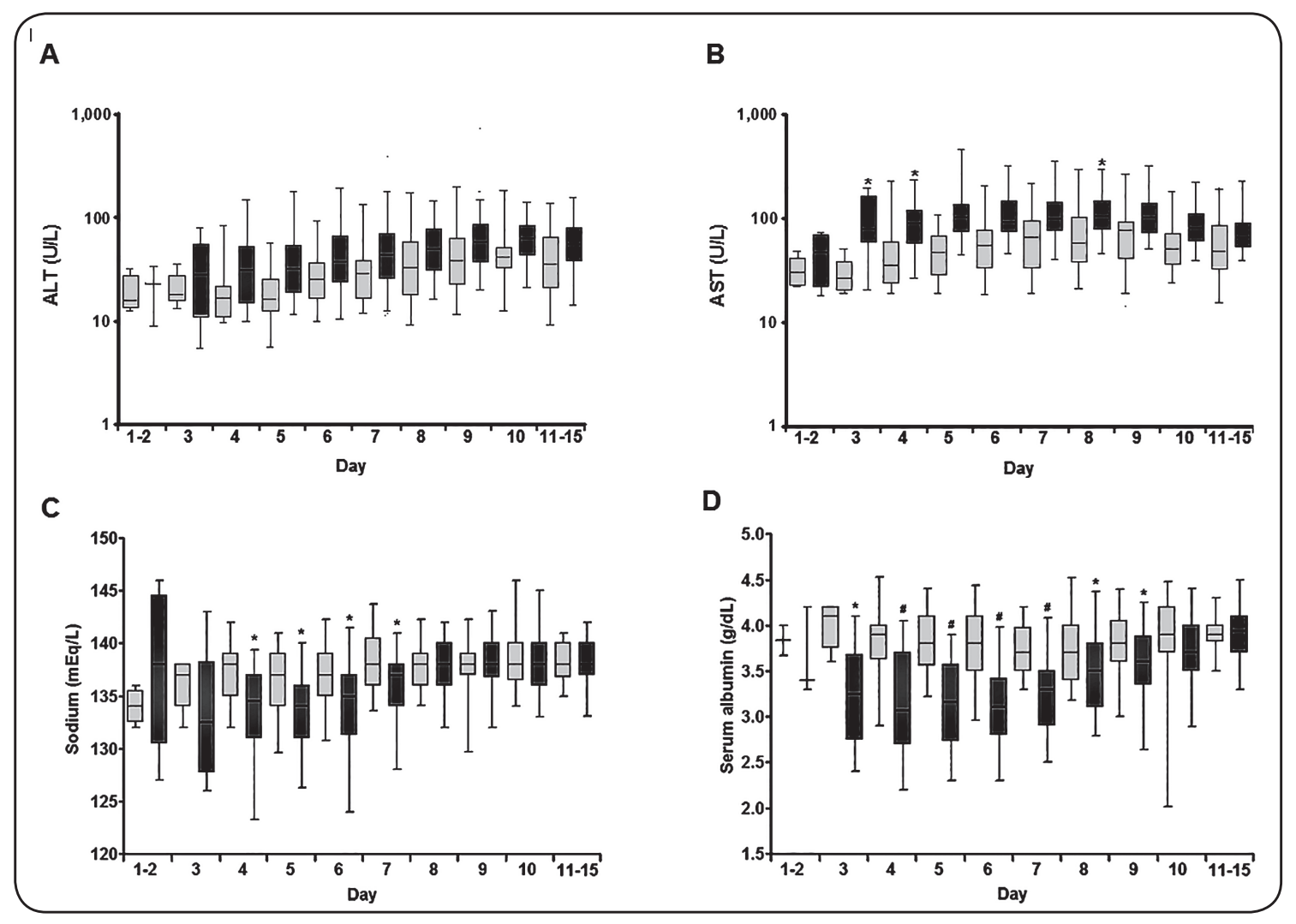

FIGURE 2: Box-plots for the A. Alanine aminotransferase (ALT), B. aspartate aminotransferase (AST), C. sodium, and D. serum albumin levels in patients with dengue hemorrhagic fever (DHF) and classical dengue (CD) who were admitted to the Hospital Municipal Hospital Jesus from January to June 2008 , according to elapsed days of illness. ${ }^{*} P<0.01$ vs. $C D ; \# P<0.05$ vs. CD. $\mathbf{n} D H F, n$ DC. 
CD. Significant hyponatremia was observed in DHF patients from the fourth day onwards (Figure 2C).

Albumin. Of the 400 patients for whom serum albumin levels were available, 291 (72.8\%) had DHF and 109 (27.2\%) had CD. Patients with DHF (but not CD) had mean serum albumin levels less than $3.5 \mathrm{~g} / \mathrm{dl}$ from day 3 to day 9 of illness. Serum albumin levels were lower for those with DHF compared to those with $\mathrm{CD}$ on days 3,8 , and $9(\mathrm{P}<0.01)$ and days $4,5,6$, and 7 ( $P<0.05$; Figure 2D).

\section{DISCUSSION}

This study showed that clinical signs and symptoms (e.g. abdominal pain and hepatomegaly) and simple tests (e.g. tourniquet test) are important markers of clinical forms of severe dengue that may predict patient's prognosis, even before laboratory test results are available.

Another finding of this study was the higher occurrence of DHF in children aged 5 years or older. Cavalcanti and colleagues $^{9}$ similarly described an increased incidence of DHF among children in Ceará/Brazil during 2007-2008. Medronho ${ }^{6}$ postulated that the severity of the 2007/2008 dengue epidemic in the State of Rio de Janeiro, with its high number of severe cases among children, may have been directly related to the lack of immunity among those born after the great epidemic in 1990/1991. Both the 1990/1991 and 2007/2008 epidemic were caused by serotype $2^{6}$. However, these patients may have had immunity against serotype 3 , which circulated in $2001 / 2002$, supporting the role of sequential infection and antibody dependent enhancement in disease severity. At the same time, it is important to emphasize that these data cannot be extrapolated to the general population since this study was conducted exclusively in children.

In addition to confirming the significant hepatic impairment in children with DHF, this study demonstrated that aminotransferase levels are important in dengue. Kuo and colleagues ${ }^{10}$, who evaluated 270 children with dengue in Thailand, found abnormal serum levels of AST, ALT, and bilirubin in $93.8 \%, 82.2 \%$, and $7.2 \%$ of cases, respectively. The authors' finding that these levels were even higher in patients with hemorrhage suggested the presence of more severe liver disease.

Souza and colleagues ${ }^{11}$ evaluated 1585 patients with serologically confirmed dengue in the City of Campos, State of Rio de Janeiro. They found that AST and ALT levels were abnormal in $63.4 \%$ and $45.0 \%$ of patients, respectively. The authors associated the high aminotransferase levels with hemorrhagic forms of dengue and hepatic inflammation, which resembled acute viral hepatitis in some cases.

Kuo and colleagues ${ }^{10}$ believe that the liver is not the primary target of dengue infection in humans, and that the higher ratio of AST to ALT may actually reflect myocyte injury that occurs at an early disease stage. Although they do not consider dengue virus to be hepatotropic, Roy and colleagues ${ }^{12}$ did acknowledge that hepatomegaly and serum aminotransferase level elevation are common among children with dengue. The degree of liver injury ranges from mild inflammation with elevated AST and mildly elevated ALT levels to fulminant hepatic failure. These authors believe that liver failure is a dengue complication related to direct viral effects or deregulation of the host immune response.

In this study, serum AST levels were higher than serum ALT levels. Furthermore, painful hepatomegaly was associated with elevated serum levels of both ALT and AST. Mohan and colleges ${ }^{13}$, studying children with dengue infection, found that hepatic dysfunction with increased levels of serum enzymes, was a common feature with or without hepatomegaly. Our finding, showing that serum AST and ALT levels were 20 times the normal values in five of the six patients who died, is consistent with previous reports of hepatic impairment in DHF. Five of the patients who died had painful hepatomegaly, gastrointestinal bleeding, and liver failure; four out of those five patients had jaundice.

According to Ranganathan and colleagues ${ }^{14}$, liver damage may result from toxicity secondary to administration of acetaminophen or other drugs to treat the acute phase of dengue. The authors based their conclusions on their study of 25 children with fulminant hepatic failure, who had received high doses of acetaminophen to treat acute viral infections.

In the present study, it was not possible to quantify acetaminophen intake prior to hospital admission. However, acetaminophen is available over-the-counter at no charge, extensively advertised in the lay media, and part of the therapeutic routine recommended by the Brazilian Ministry of Health ${ }^{8}$ for self-treatment of dengue symptoms. Repeated acetaminophen use, even at therapeutic doses, may increase serum aminotransferase levels; inadvertent use of high doses may lead to severe liver injury and death ${ }^{15-17}$. Considering, the high frequency of hepatic impairment observed in this study, we advise that acetaminophen be used with caution in cases of DHF.

Cutaneous bleeding occurred upon use of the tourniquet test in $90.8 \%$ of patients with DHF and $39.2 \%$ of patients with CD; a positive tourniquet test was independently associated with DHF. Other authors ${ }^{18,19}$ have also highlighted the importance of the positive tourniquet test in predicting dengue severity, suggesting that this procedure allows for early diagnosis and treatment, which are essential for preventing dengue-related death.

Other spontaneous hemorrhagic manifestations occurred with high frequency but less severity among patients with DHF and CD in our study, but severe bleeding was only observed in patients with DHF. Our findings for hemorrhage are similar to those reported previously ${ }^{18,20}$.

In the present study, plasma leakage was common, as evidenced by high rates of hypoalbuminemia $(80.0 \%)$, pleural effusion $(78.7 \%)$, hemoconcentration $(70.0 \%)$, and ascites $(65.5 \%)$. In this study, patients who received volume resuscitation often had resolution of hemoconcentration. Therefore, it is necessary to assess other markers of plasma leakage to increase diagnostic sensitivity for DHF.

Serum albumin may be used as a surrogate marker of hemoconcentration to diagnose DHF, as the test is simple, inexpensive, and can be performed quickly in health care settings.

Patients with DHF and CD in this study differed with respect to occurrence of hyponatremia. Among the many explanations 
for this difference is that by Mekmullica and colleagues ${ }^{21}$, who believe that sodium depletion occurs secondary to inappropriate antidiuretic hormone secretion and sodium loss in the urine due to acute tubular necrosis.

Leukocytosis occurred after day 5 of illness in five of six patients with DHF who died. This white blood cell count abnormality typically suggests bacterial infection, but it is also characteristic of patients with DHF who have rapid disease progression. Thus, dengue should remain part of the differential diagnosis in patients with leukocytosis ${ }^{22}$.

In this study, patients with DHF had more pronounced thrombocytopenia compared to those with $\mathrm{CD}$. This difference was apparent throughout the first week of illness and partly into the second week. Platelet levels below 100,000 platelets/ml occurred even in patients with CD and no other signs of DHF; thus, other diagnostic criteria are needed to distinguish DHF from $\mathrm{CD}$.

Furthermore, Srikiatkanchorn and Green ${ }^{23}$ have reported that blood loss is common among patients with $\mathrm{CD}$ and DHF, although it is more severe (particularly in the gastrointestinal tract) among those with DHF. Thus, platelet counts may also be useful to monitor disease progression.

This study was limited by its design based on medical record review. This type of study is subject to bias resulting from loss of medical records, inconsistent quality of recorded data, and incomplete test results. In addition, our study results may have been influenced by the use of a single hospital site as well as the inclusion criteria using clinical and epidemiologic criteria to confirm $21.5 \%$ of the included cases.

In 2009, the World Health Organization proposed a new classification, adopted by the Brazilian Ministry of Health since 2014: dengue without warning signs, dengue with warning signs, and severe dengue. Macedo and collegues ${ }^{24}$ demonstrated that the revised scheme had better sensitivity in children in Rio de Janeiro to assess severe cases, which may potentially avoid deaths. However, the traditional scheme showed superiority in distinguishing truly severe cases and avoiding workload on the health system.

Nevertheless, this study was able to identify important clinical and laboratory factors associated with the diagnosis and evolution of CD and DHF in hospitalized patients aged 16 years and younger. In line with other pediatric studies ${ }^{25,26}$, the identification of simple clinical signs (e.g. hepatomegaly), symptoms (e.g. abdominal pain), and tests (e.g. tourniquet test) to determine dengue severity may be useful for healthcare providers even before diagnostic laboratory tests can be performed. Finally, considering the high frequency of hepatic impairment in pediatric patients with DHF in this study, the therapeutic routine suggested by the Ministry of Health ${ }^{8}$ should be reassessed.

\section{Acknowledgments}

We would like to thank the general practitioners from the Hospital Municipal Jesus, Rio de Janeiro, RJ, Brazil, for their help in collecting the clinical and therapeutic data from the patients.

\section{Conflict of Interest}

The authors declare that there is no conflict of interest.

\section{REFERENCES}

1. Sharp TM, Tromashek KM, Red JS, Margolis HS, Waterman SH. A new look at an old disease: Recent insights into the global epidemiology of dengue. Curr Epidemiol Rep. 2017;4(1):11-21.

2. Kulkarni MJ, Sarathi V, Bhalla V, Shivpuri D, Acharya U. Clinicoepidemiological profile of children hospitalized with dengue. Indian J Pediatr 2010; 77:1103-07.

3. Gubler DJ. Epidemic dengue/dengue hemorrhagic fever as a public health, social and economic problem in the 21st century. Trends Microbiol. 2002;10(2):100-3.

4. Siqueira JB Jr, Martelli CM, Coelho GE, Simplicio AC, Hatch DL. Dengue and dengue hemorrhagic fever, Brazil, 1981-2002. Emerg Infect Dis. 2005;11(1):48-53.

5. Rocha LA, Tauil PL. Dengue em crianças: aspectos clínicos e epidemiológicos, Manaus, estado do Amazonas, no período de 2007 e 2007. Rev Soc Bras Med Trop. 2009; 42(1):18-22.

6. Medronho RA. Dengue: aumento da gravidade e deslocamento para a infância. Cad. Saúde Colet. Rio de Janeiro. 2009; 17:301-4.

7. Rio de Janeiro. Secretaria Municipal de Saúde. Internações hospitalares do SUS Dados Oficiais - MS/SMS/Rio de Janeiro. Disponível em http://tabnet.rio.rj.gov.br/cgi-bin/dh?sihd2/ definicoes/oxrj.def. Accessed on 22/12/2017.

8. Ministério da Saúde (MS). Secretaria de Vigilância em Saúde. Informe epidemiológico do dengue. Diagnóstico e manejo clínico. Brasília. $4^{\text {o }}$ Edição. Brasília: MS 2013. 79p.

9. Cavalcanti LP, Vilar D, Souza-Santos R, Teixeira MG. Change in age pattern of persons with dengue, Northeastern Brazil. Emerg Infect Dis. 2011;17(1):132-4.

10. Kuo CH, Tai DI, Chang-Chien CS, Lan CK, Chiou SS, Liaw YF. Liver biochemical tests and dengue fever. Am J Trop Med Hyg.1992;47(3):265-70.

11. Souza LJ, Alves JG, Nogueira RM, Gicovate Neto C, Bastos DA, Siqueira EW, et al. Aminotransferase changes and acute hepatitis in patients with dengue fever: analysis of 1,585 cases. Braz J Infect Dis. 2004;8(2):156-63.

12. Roy A, Sarkar D, Chakraborty S, Chaudhuri J, Ghosh P, Chakraborty S. Profile of hepatic involvement by dengue virus in dengue infected children. N Am J Med Sci. 2013;5(8):480-5.

13. Mohan B, Patwari AK, Anand VK. Hepatic dysfunction in childhood dengue infection. J Trop Pediatr. 2000;46(1):40-3.

14. Ranganathan SS, Sathiadas MG, Sumanasena S, Fernandopulle M, Lamabadusurriya SP, Fernandopulle BM. Fulminant hepatic failure and paracetamol overuse with therapeutic intent in febrile chidren. Indian J Pediatr. 2006;73(10):871-5.

15. Mahadevan SB, McKiernan PJ, Davies P, Kelly DA. Paracetamol induced hepatotoxicity. Arch Dis Child. 2006;91(7):598-603.

16. Dart RC, Bailey E. Does therapeutic use of acetaminophen cause acute liver failure? Pharmacotherapy. 2007;27(9):1219-30.

17. Gan SC, Chong SY, Lum SC, Lee WS. Regular paracetamol in severe dengue: a lethal combination. Singapore Med J. 2013;54(2):e35-7.

18. Phuong CX, Nhan NT, Kneen R, Thuyu PT, van Thien C, Nga NT, et al. Clinical diagnosis and assessment of severity of confirmed dengue infections in Vietnamese children: is the world health organizatioin classification system helpful? Am J Trop Med Hyg. 2004;702(2):172-9. 
19. Moraes GH, de Fátima Duarte E, Duarte EC. Determinants of mortality from severe dengue in Brazil: a population-based casecontrol study. Am J Trop Med Hyg. 2013;88(4):670-6.

20. Britto CAA, Albuquerque MFMP, Lucena-Silva N. Evidência de alterações de permeabilidade vascular no dengue: quando a dosagem de albumina sérica define o quadro. Rev Soc Bras Med Trop. 2007;40(2):220-33.

21. Mekmullica J, Suwanphatra A, Thienpaitoon H, Chansongsakul T, Cherdkiatkul T, Pancharoen C, et al. Serum and urine sodium levels in dengue patients. Southeast Asian J Trop Med Public Health. 2005;36(1):197-9

22. Vita WP, Nicolai CCA, Azevedo MB, Souza MF, Baran M. Dengue: alertas clínicos e laboratoriais da evolução grave da doença. Rev Bras Clin Med. 2009;7(1):11-4.
23. Srikiatkhachorn A, Grenn S. Markers of dengue disease severity in AL Rothman (ed). Dengue virus, Currents Topics in Microbiology and Immunology. Springer-Verlag Berlin Heidelberg. 2010. P. 67-82.

24. Macedo GA, Gonin MLC, Pone SM, Cruz OG, Nobre FF, Brasil P. Sensitivity and specificity of the World Health Organization dengue classification schemes for severe dengue assessment in children in Rio de Janeiro. PLoS One. 2014;9(4):e96314.

25. Pires Neto RJ, de Sá SLB, Pinho SC, Pucci FH, Teófilo CR, Evangelista PD, et al. Dengue infection in children and adolescents: Clinical profile in a reference hospital in northeast Brazil. Rev Soc Bras Med Trop. 2013;46(6):765-8.

26. Giraldo D, Sant'Anna C, Périssé AR, March MF, Souza AP, Mendes A, et al. Characteristics of children hospitalized with dengue fever in an outbreak in Rio de Janeiro, Brazil. Trans R Soc Trop Med Hyg. 2011;105(10):601-3. 